\title{
What Patients Want: Preferences Regarding Hospital Pharmacy Services
}

\author{
Odette Gould, Paula Buckley, and Douglas Doucette
}

\begin{abstract}
Background: The role of hospital pharmacists has evolved over the past couple of decades from preparation and distribution of medications to active involvement in health care teams, through identification and resolution of patients' medication-related issues in an effort to improve patient outcomes. However, patients' preferences about pharmacy services are not well known.
\end{abstract}

Objective: To use content analysis of open-ended survey responses from recently discharged patients to determine desired pharmacy services.

Methods: Former inpatients were randomly selected for participation in a telephone survey following discharge from acute care hospitals in the Horizon Health Network in New Brunswick. The survey included the question, "What service or information would you like a pharmacist to provide in the hospital that would most help you in managing your medications?" For responses to this question, 2 raters established response categories, obtained acceptable inter-rater agreement, and independently scored the responses.

Results: Four global categories of responses were obtained, each having multiple subcategories. Of the 703 responses (from 325 respondents), $445(63.3 \%)$ were related to the category "information about medications", including purpose, adherence, and side effects. The second most common response category was "self-disclosure" (167 [23.8\%]), including experiences with pharmacies, medications, or hospitals. Less frequently, responses pertained to "pharmacy services" (54 [7.7\%]), such as medication costs and continuity of care, and to "information source for medications" (37 [5.3\%]).

Conclusions: Most respondents to this survey wanted hospital pharmacists to provide a general medication overview, including information about side effects and interactions, during their admission. The results suggest that many patients are unaware of other potential clinical services that pharmacists can provide. A future study could assess patients' willingness to select from a guiding list of potential clinical services.

Key words: clinical pharmacy services, expanded pharmacy services, patient expectations

\section{RÉSUMÉ}

Contexte : Le rôle des pharmaciens d'hôpitaux a évolué au cours des vingt dernières années de la préparation et de la distribution des médicaments à la participation active au sein des équipes de soins, en contribuant à la détection et à la résolution des problèmes liés aux médicaments dans un effort pour améliorer les résultats thérapeutiques. Toutefois, on connait mal les préférences des patients quant aux services de pharmacie.

Objectif : Effectuer une analyse du contenu des réponses données par les patients venant d'obtenir leur congé de l'hôpital aux questions ouvertes d'un sondage afin de préciser les services de pharmacie souhaités.

Méthodes : Des patients qui avaient été hospitalisés ont été choisis au hasard pour répondre à un sondage téléphonique après avoir reçu leur congé d'hôpitaux de soins de courte durée du Réseau de santé Horizon du Nouveau-Brunswick. Le sondage incluait la question suivante : "Quel service ou quelle information aimeriez-vous que le pharmacien vous fournisse à l'hôpital pour vous aider à mieux gérer vos médicaments? » En ce qui concerne les réponses à cette question, deux évaluateurs ont déterminé les catégories de réponses, obtenu une entente inter-évaluateurs acceptable et attribué une cote indépendante aux réponses.

Résultats : Quatre grandes catégories de réponses ont été définies, chacune possédant plusieurs sous-catégories. Des 703 réponses (de 325 répondants), 445 (63,3\%) avaient trait à la catégorie « information sur les médicaments ", incluant le but, l'observance et les effets secondaires. La deuxième catégorie de réponses la plus courante était l'« ouverture personnelle » (167 [23,8\%]), incluant l'expérience des répondants avec les pharmacies, les médicaments ou les hôpitaux. Dans une moindre mesure, les réponses avaient trait aux « services de pharmacie " $(54$ [7,7 \%]), comme le coût des médicaments et la continuité des soins, et à la « source d'information sur les médicaments » (37 [5,3\%]).

Conclusions : La plupart des répondants à ce sondage désiraient que les pharmaciens d'hôpitaux leur donnent des renseignements généraux sur les médicaments, notamment de l'information sur les effets secondaires et les interactions, pendant leur séjour. Les résultats suggèrent également que de nombreux patients ignorent les autres services cliniques potentiels que les pharmaciens peuvent leur fournir. Une prochaine étude pourrait évaluer la volonté des patients à choisir les services cliniques potentiels d'une liste de référence.

Mots clés : services de pharmacie clinique, services de pharmacie élargis, attentes des patients

[Traduction par l'éditeur] 


\section{INTRODUCTION}

$\mathrm{O}$ ver the past 20 years, the role of hospital pharmacists has changed dramatically, from the preparation and distribution of medication to participation in multidisciplinary care teams, where they play an active part in medication management, with a focus on evidence-informed drug therapies to improve patient outcomes. Several studies have evaluated hospital-based pharmacy services or patients' expectations of those services ${ }^{1-6}$ Morecroft and others ${ }^{1}$ interviewed patients admitted to acute medical wards and found that the majority of respondents expected to see a pharmacist and to ask questions about how their drug therapy worked and about possible medication effects. In that study, 58\% of respondents reported talking with a pharmacist during their admission. ${ }^{1}$ In another study by the same author group, ${ }^{2} 35 \%$ of inpatients stated that they were surprised by and satisfied with the pharmacist's involvement in their care and treatment. In the same study, $23 \%$ of participants reported that their expectations were exceeded and that the pharmacist had performed some activities expected of the attending doctor. However, an equal proportion (23\%) thought that pharmacists were "silent partners", having very little or no contact with patients.?

Another group of researchers ${ }^{3}$ surveyed 315 patients to measure expectations of and satisfaction with pharmacy services. They found that cognitive services were best evaluated from the patient's perspective, through questions about how the services compared with what patients expected. Asking patients how their recent experiences compared with past experiences made it possible to evaluate tangible aspects of the services, such as printed information and wait time. The researchers concluded that satisfaction surveys should be designed to specifically assess the type of services provided by the pharmacy. ${ }^{3}$

Patient satisfaction is an important element in evaluating the quality of health care services from the patient's perspective and in predicting how patients will behave after receiving services. A patient compares his or her experience with prior expectations, and the level of satisfaction depends on whether the patient's experience was superior to, inferior to, or the same as expectations. ${ }^{7}$ Clearly, the relationship between what patients expect and what is satisfactory to them is complex. Pharmacists can best fulfill their expanded role in providing direct patient care services if they understand the role that patients expect them to play in their health care. ${ }^{8}$ One means of accomplishing this is to ask patients how their needs can be better met through provision of a service or product. ${ }^{7}$ Another dimension that is particularly relevant when measuring satisfaction with services is whether patients recall meeting with a pharmacist, particularly in the hospital setting. As part of an evaluation of services by the Calgary Health Region, Romonko Slack and Ing' determined the baseline number of patients who recalled meeting with a pharmacist during a recent hospital visit and how satisfied they were with this service. Of the almost 400 respondents, $20.9 \%$ remembered receiving a visit from a pharmacist during their hospital stay, although satisfaction ratings were quite high among this group. Romonko Slack and Ing hoped that their survey would help pharmacists reach the goal of having $50 \%$ of patients recall interaction with a pharmacist during a hospital stay. ${ }^{9}$

Research into patient expectations for pharmacy services in hospital indicates that tailored services and information about medications is beneficial to patients during the transition from hospital to home. ${ }^{10,11}$ MacAulay and others ${ }^{10}$ examined the effects of including a pharmacist as part of an extramural (home care) program for high-risk patients. The patients had complex medical conditions, were taking multiple medications, and had recently been discharged from hospital. As part of the home care team, the pharmacist identified and intervened on many medication-related issues, with the goal of optimizing patients' medication regimens. The majority of interventions were implemented during the first and second visits, with $22 \%$ of all interventions being related to adherence or patient education. Both patients and other members of the health care team were very satisfied with the provision of clinical pharmacy services as part of home care. Borgsteede and others ${ }^{11}$ reasoned that changes to medication regimens after hospital admission may lead to patient harm if patients are insufficiently informed about the changes at the time of discharge. Noting that most educational activities at discharge are based on opinions of health care professionals, these authors interviewed patients at discharge and asked what medication topics they would like covered to facilitate their transition from hospital to home. They found that most patients wanted general information about their medications, the side effects of those medications, and alternatives; some patients wanted details, whereas others did not. The authors proposed that the health care professional's primary task is to identify each individual patient's needs, to effectively communicate the most essential information during patient counselling, and to avoid "maximal information transfer".

In the Horizon Health Network, a regional health authority in New Brunswick, a telephone survey method similar to that used by Romonko Slack and Ing9 was employed to establish a baseline of patient recall and level of satisfaction with interactions with a pharmacist during hospital admission. The survey showed that $46.1 \%$ of former inpatients recalled interacting with a pharmacist, and $89.1 \%$ were "satisfied" or "very satisfied" with such encounters, as reported in a companion paper. ${ }^{12}$ In addition to questions about interactions with a pharmacist, the survey included a question to elicit patients' preferences for current or new clinical pharmacy services. This report describes the content analyses for responses to this open-ended question. 


\section{METHODS}

A standardized telephone survey was administered to acute care patients recently discharged from hospitals in the Horizon Health Network, New Brunswick. Horizon Health Network is the largest health authority in Atlantic Canada, employing approximately 13000 staff and 1000 physicians in more than 100 facilities, clinics, and offices. This regional health authority has approximately 1600 hospital beds across 12 hospitals located in both rural and urban areas of New Brunswick.

\section{Participants}

Acute care patients who had been discharged from 9 hospitals during 3 months in 2010 (March, November, and December) were included in the study. Of 2004 former inpatients discharged from 27 units, 1028 were screened, and 399 completed the phone survey. Patients were excluded if any of the following criteria applied: age less than 18 years; length of stay less than $24 \mathrm{~h}$; death, discharge to a nursing home or special care facility, or transfer to another acute care unit or facility; presence of a medical condition limiting the person's ability to recall or provide information (e.g., dementia, Mini Mental State Examination less than 23/30, clock score less than 9, verbal or hearing impairment).

\section{Procedure}

Prospective participants were identified from lists of patients discharged from each eligible facility, as described in the companion article. ${ }^{12}$ Potential participants were randomly selected from the lists by pharmacy staff or students, who also served as interviewers, and attempts were made to contact them by telephone. After verbal informed consent was obtained, the survey was administered, in English or French, according to a prepared script, ${ }^{12}$ and the interviewer recorded the responses. The complete questionnaire is available as an online appendix with the companion paper. $^{12}$ This paper reports on data obtained in response to the following open-ended question: "What service or information would you like a pharmacist to provide in the hospital that would most help you in managing your medications?" The Research Ethics Board of Horizon Health Network approved the project as a minimal risk study.

\section{Sample Size}

For the primary outcome of the main study (patients' recall of an interaction with a hospital pharmacist), a Bayesian method was used to determine that 384 respondents were needed to detect an estimated prevalence of 50\% with 95\% confidence. ${ }^{13}$ Recent separation lists provided by the Health Records department indicated that the 27 patient care units participating in the study discharged an average of 1530 patients per month. A specific sample size was not determined for the content analysis reported here.

\section{Data Analysis}

Content analysis of the open-ended responses was carried out in the following manner. Two scorers worked together to review the responses from a subsample of 10 participants. On the basis of that review, a preliminary set of response categories was established. Subsequently, a second set of 20 participant responses were scored independently by the 2 coders using these categories, and inter-rater agreement was calculated for 2 aspects of scoring: the number of items present in a participant's response (i.e., segmentation) and the categorization of each item identified (i.e., content categorization). Thus, each person's statement could contain one or more "segments", and each segment was coded into one and only one category. After inter-rater reliability had been established, each disagreement in coding was discussed. This discussion led to the creation of new categories, the refinement of existing category definitions, and the grouping of conceptually related categories. This process was repeated iteratively for groups of 20 participants for the entire set of responses, and overall inter-rater reliability was calculated. Finally, any mention of particular medications or categories of medications was noted.

Frequencies were calculated for each category. The data represent the number of occurrences of each category of response. One person's response might contain more than one occurrence per category. For example, a participant's statement that she would like to know "/how many tablets to take/ and when to take the tablets/" was segmented as 2 responses, with both items counted in the time/dosage category. The $\chi^{2}$ goodness-of-fit test, using critical $\alpha=0.05$, with the associated effect-size indicator (i.e., Cramer's V) ${ }^{14}$ was used to test the hypothesis that the number of occurrences of each category differed across groups. The effect size indicates the percent variance in the scores that was accounted for by the independent variable. The following group comparisons were used: men versus women; small rural hospitals versus large urban hospitals; and age groups, namely young adults (18-55 years), middle-aged adults (56-65 years), young-old adults (66-75 years), and oldest adults (76-99 years).

\section{RESULTS}

Of 399 former inpatients who completed the phone questionnaire, 325 responded to the open-ended question regarding what hospital pharmacy services would be most helpful. The sample consisted of 185 (56.9\%) women and 140 (43.1\%) men. Participants ranged in age from 19 to 94 years (mean 66.7 years, standard deviation 15.2). For the purpose of analyses, the participants were divided into 4 age groups: 63 
(19.4\%) young adults, $76(23.4 \%)$ middle-aged adults, 85 (26.2\%) young-old adults, and $101(31.1 \%)$ oldest adults. Sixty-five patients $(20 \%)$ had been discharged from small rural hospitals and 260 (80\%) from large urban hospitals.

Overall, 703 interpretable statements were obtained. The total agreement rate for segmenting responses into individual items was $92.5 \%$, and the total agreement rate for coding items into response categories was $85.9 \%$. The content analysis yielded 4 global categories of responses, each having multiple subcategories. Category labels and examples from the data set for each category and subcategory are provided in Table 1 , as well as the frequency of each type of response. The first global category, the provision of information regarding medication and adherence, was closely linked to the traditional counselling role of hospital pharmacists. The second global category, pharmacy services, included statements about perceptions of what the role of a hospital pharmacist is or should be. Responses included in the last 2 categories could be interpreted as indicating respondents' misunderstanding of the interview question; nonetheless, categories were created to allow coding of all interpretable responses. The third category, self-disclosure, included statements describing patients' positive and negative evaluations of their interactions with pharmacists at the hospital. Within this category, evaluations of hospital

Table 1. Definitions of Categories with Examples and Frequency

\begin{tabular}{|c|c|c|c|}
\hline \multirow{2}{*}{$\begin{array}{l}\text { Category } \\
\text { Information about medication }\end{array}$} & \multirow[t]{2}{*}{ Examples } & \multicolumn{2}{|c|}{$\begin{array}{l}\text { No. }(\%) \text { of Responses } \\
\quad(n=703)\end{array}$} \\
\hline & & 445 & $(63.3)$ \\
\hline General information & & 224 & (31.9) \\
\hline Medication overview & Explaining the basics & & \\
\hline & Going over all medications & 105 & $(14.9)$ \\
\hline Medication purpose & $\begin{array}{l}\text { What drugs are for and how they work } \\
\text { Know why you take it }\end{array}$ & 83 & $(11.8)$ \\
\hline New medications & $\begin{array}{l}\text { Go over new prescriptions } \\
\text { Consult on medication changes }\end{array}$ & 29 & (4.1) \\
\hline $\begin{array}{l}\text { Over-the-counter and } \\
\text { home medications }\end{array}$ & $\begin{array}{l}\text { Answer questions on vitamins and supplements } \\
\text { Answer questions on natural health products }\end{array}$ & 7 & (1.0) \\
\hline Adherence information & & 73 & $(10.4)$ \\
\hline Timing/dosage & $\begin{array}{l}\text { How to take medications } \\
\text { Dosage requirements }\end{array}$ & 65 & $(9.2)$ \\
\hline Compliance aids & $\begin{array}{l}\text { Bubble packs } \\
\text { Advise how to keep all medications together }\end{array}$ & 8 & (1.1) \\
\hline Potential adverse effects & & 148 & $(21.1)$ \\
\hline Side effects & $\begin{array}{l}\text { Side effects } \\
\text { What could go wrong and why }\end{array}$ & 91 & (12.9) \\
\hline Allergies & Drug allergies & 8 & $(1.1)$ \\
\hline Interactions & $\begin{array}{l}\text { Make sure there are no conflicts with diabetes } \\
\text { Compatibility of drug, check for interactions }\end{array}$ & 49 & $(7.0)$ \\
\hline Pharmacy services & & 54 & (7.7) \\
\hline $\begin{array}{l}\text { Accuracy and timely provision } \\
\text { of medications }\end{array}$ & $\begin{array}{l}\text { Delivery of medications } \\
\text { Monitor who and where medications go to }\end{array}$ & 16 & (2.3) \\
\hline Linkage and costs & $\begin{array}{l}\text { Less conflict between home pharmacist and hospital care } \\
\text { Encourage to review with family doctor after } \\
\text { Less expensive drugs }\end{array}$ & 19 & $(2.7)$ \\
\hline Continuity of care during stay & $\begin{array}{l}\text { Would love to see more pharmacy involvement } \\
\text { Make sure everything is set up before patient leaves }\end{array}$ & 19 & $(2.7)$ \\
\hline Self-disclosure & & 167 & (23.8) \\
\hline Positive pharmacy experience & $\begin{array}{l}\text { Treated very well } \\
\text { Very satisfied, no complaints, handled well }\end{array}$ & 45 & $(6.4)$ \\
\hline Negative pharmacy experience & $\begin{array}{l}\text { Would have liked to meet with a pharmacist } \\
\text { Didn't see any real medication updates during visit }\end{array}$ & 26 & (3.7) \\
\hline Other & [Self-disclosures not relevant to question asked] & 96 & $(13.7)$ \\
\hline Information source & & 37 & (5.3) \\
\hline $\begin{array}{l}\text { Patient depends on nurses } \\
\text { and doctors }\end{array}$ & $\begin{array}{l}\text { Went over everything with nurses } \\
\text { Has been followed by a doctor since age } 30 \text { so doesn't feel } \\
\text { need any additional help }\end{array}$ & 4 & $(0.6)$ \\
\hline $\begin{array}{l}\text { Patient depends on community } \\
\text { pharmacist }\end{array}$ & $\begin{array}{l}\text { Already familiar with her medications; is fine with her knowledge } \\
\text { Community pharmacist answers any medication questions }\end{array}$ & 33 & $(4.7)$ \\
\hline
\end{tabular}


Table 2. Responses by Sex

\begin{tabular}{|c|c|c|c|c|}
\hline \multirow[b]{2}{*}{ Category } & \multicolumn{2}{|c|}{ No. (\%) of Respondents* } & \multirow[b]{2}{*}{$p$ valuet } & \multirow[b]{2}{*}{ Cramer's V $\ddagger$} \\
\hline & $\begin{array}{c}\text { Men } \\
(n=140)\end{array}$ & $\begin{array}{l}\text { Women } \\
(n=185)\end{array}$ & & \\
\hline Information about medication & & & & \\
\hline General information & $74(53)$ & $82(44)$ & 0.13 & 0.08 \\
\hline Adherence information & $25(18)$ & $41(22)$ & 0.34 & 0.05 \\
\hline Potential adverse effects & $56(40)$ & $62(34)$ & 0.23 & 0.07 \\
\hline Pharmacy services & $21(15)$ & $23(12)$ & 0.50 & 0.04 \\
\hline Self-disclosure & $51(36)$ & $78(42)$ & 0.29 & 0.06 \\
\hline Information source & $11 \quad(8)$ & $25(14)$ & 0.11 & 0.09 \\
\hline
\end{tabular}

*Number of respondents who used the category at least once.

†Chi-squared test.

\#Effect size for comparisons between men and women.

Table 3. Responses by Age Group

\begin{tabular}{|c|c|c|c|c|c|c|}
\hline \multirow[b]{2}{*}{ Category } & \multicolumn{4}{|c|}{ Age Group; No. (\%) of Respondents* } & \multirow[b]{2}{*}{$p$ valuet } & \multirow[b]{2}{*}{ Cramer's V $\ddagger$} \\
\hline & $\begin{array}{l}18-55 \mathrm{yr} \\
(n=63)\end{array}$ & $\begin{array}{l}56-65 \mathrm{yr} \\
(n=76)\end{array}$ & $\begin{array}{l}66-75 \mathrm{yr} \\
(n=85)\end{array}$ & $\begin{array}{l}76-99 \mathrm{yr} \\
(n=101)\end{array}$ & & \\
\hline \multicolumn{7}{|c|}{ Information about medication } \\
\hline General information & $29(46)$ & $49(64)$ & $47(55)$ & $31(31)$ & $<0.001$ & 0.26 \\
\hline Adherence information & $15(24)$ & $14(18)$ & $13(15)$ & $24(24)$ & 0.44 & 0.09 \\
\hline Potential adverse effects & $27(43)$ & $34(45)$ & $35(41)$ & $22(22)$ & 0.004 & 0.20 \\
\hline Pharmacy services & $12(19)$ & $10(13)$ & $11(13)$ & $11(11)$ & 0.52 & 0.08 \\
\hline Self-disclosure & $18(29)$ & $32(42)$ & $26(31)$ & $53(53)$ & 0.004 & 0.20 \\
\hline Information source & $8(13)$ & $6(8)$ & $6(7)$ & $16(16)$ & 0.20 & 0.12 \\
\hline
\end{tabular}

*Number of respondents who used the category at least once.

+Chi-squared test.

‡Effect size for comparisons between age groups.

Table 4. Responses by Size and Type of Hospital

Type of Hospital;

No. (\%) of Respondents*

\begin{tabular}{lrrrr} 
Category & $\begin{array}{c}\text { Small Rural } \\
(\boldsymbol{n}=\mathbf{6 5})\end{array}$ & $\begin{array}{c}\text { Large Urban } \\
(\boldsymbol{n}=\mathbf{2 6 0})\end{array}$ & $\boldsymbol{p}$ valuet & Cramer's V $\neq$ \\
Information about medication & $38(58)$ & $118(45)$ & 0.06 & 0.10 \\
General information & $13(20)$ & $53(20)$ & 0.94 & 0.004 \\
Adherence information & $20(31)$ & $98(38)$ & 0.30 & 0.06 \\
Potential adverse effects & $7(11)$ & $37(14)$ & 0.47 & 0.04 \\
\hline Pharmacy services & $20(31)$ & $109(42)$ & 0.10 & 0.09 \\
\hline Self-disclosure & $13(20)$ & $23(9)$ & 0.010 & 0.14 \\
\hline Information source & 13 & &
\end{tabular}

*Number of respondents who used the category at least once.

†Chi-squared test.

\#Effect size for comparisons between hospital types.

experiences that were not directly relevant to pharmacy services were categorized as "other". The fourth category, information source, included statements about participants' preference for obtaining medication information from sources other than the hospital pharmacist. The most frequent requests were for an overview of all medications (14.9\% of all responses), for information about potential side effects (12.9\%), and for information about the purpose of the medication (11.8\%) (Table 1).

Some participants mentioned particular medications or medical issues that they would have liked to discuss while in hospital. The following medications or medication-related issues were specifically mentioned: antibiotics, psychotic medication, warfarin, penicillin, insulin, puffer/lung medication, morphine, blood pressure medications, diabetic pills, anxiety pills, vitamins and supplements, natural health products, and breast-feeding while taking medication.

There were few differences in responses when patients were categorized by age (Table 2 ), sex (Table 3 ), or hospital type (small rural versus large urban; Table 4). The middle 2 age groups (56-65 and 66-75 years) were more likely than the 
2 extreme age groups to want general information and to be advised of potential adverse effects of their medications. The oldest group was more likely than younger groups to selfdisclose information about medications or their hospital experience.

\section{DISCUSSION}

Content analysis of narrative responses to a telephone questionnaire of former inpatients regarding their preferences for clinical pharmacy services led to grouping of responses into global categories of general information on medication or adherence, pharmacy services, self-disclosure, and information source. Patients were primarily concerned about receiving a list of their current medications, finding out why they needed to take them, and learning about potential side effects.

Patient satisfaction is one important indicator of quality of care, because it reflects whether or not a given service is meeting patients' expectations and is consistent with their values. ${ }^{3}$ Consumers' level of satisfaction has been described as a result of their comparison of expectations of the service with actual experience of the service. ${ }^{7}$ One's satisfaction with the service, or how one feels about the service experience, is affected by the gap between expectation and experience. ${ }^{3}$ Romonko Slack and Ing9 reported that $83 \%$ of former inpatients who recalled meeting a pharmacist during admission were satisfied or very satisfied with the encounter. Among open-ended comments from patients who participated in the survey reported here, only $7.7 \%$ were categorized as being related to pharmacy services. We speculate that few patients suggested they would like information about adherence aids, possible interactions with over-the-counter medications, and help with linkages to community pharmacies in part because they were unaware that hospital pharmacists could provide such helpful advice. Conversely, their high satisfaction level with the pharmacy services available to them as inpatients may have been related to low expectations. Anecdotal information indicates that some patients are surprised to find pharmacists interacting with them at the bedside, rather than being relegated to the traditional roles of preparing and distributing medications. More work is needed to increase public awareness of and expectations for enhanced services and thus to encourage acceptance of this shift in the professional roles and responsibilities of pharmacists.

The diversity of responses regarding patients' preferences for information or services from a hospital pharmacist indicates that a one-size-fits-all approach may not optimally prepare patients for improved outcomes with their medication regimens following hospital discharge. MacAulay and others ${ }^{10}$ examined the effects of implementing a pharmacist as part of an extramural (home care) program for high-risk patients. Pharmacy services were provided for at least 3 weeks to highrisk patients recently discharged from the hospital. The main goals of that study were to establish whether issues arose immediately after discharge or later and whether issues that the pharmacist could address would be considered clinically important. The authors found that the time spent with patients declined with each visit, the greatest number of issues being addressed during the first visit. On average, 3.6 medication-related issues were addressed per patient, and the average clinical significance of recommendations made was 4.1 on a scale ranging from 1 (potentially adverse) to 6 (life threatening). Patients and other members of the health care team were very satisfied with the work of the pharmacist (mean satisfaction scores 9.9 and 9.6 out of 10 , respectively). ${ }^{10}$ These findings clearly emphasize that tailoring of information and services, particularly those relating to the transition from hospital to home, is highly prized by patients and is also clinically important.

The findings of Borgsteede and others ${ }^{11}$ bear striking similarities to the results of the content analysis of responses collected in this study. Those investigators focused on patients at discharge, with a particular interest in what information the patients wanted to achieve a smooth transition from hospital to home. To investigate the issue, they used a semistructured questionnaire to interview 31 recently discharged patients. During the interviews, they specifically asked what medication topics patients would like covered at discharge. The authors reasoned that inclusion of patients in information transfer allows them to learn about optimal drug use and improves their knowledge about medication. Ultimately, the more patients know about their medications, the more likely they are to adhere properly to their medication regimen. After evaluating and coding the data, the researchers determined that patients had 4 major points of interest: basic information about medications, information about side effects, information about alternatives, and information about what to do when medication problems are encountered. They also found that patients preferred a combination of oral instructions and written information; there were no differences between sexes or among age groups. ${ }^{11}$

The strengths of the current study included participation by a group of former inpatients representing a wide range of ages who had been discharged from various clinical services (e.g., medical, surgical, oncology), some of whom did not receive discharge counselling by a pharmacist, although the exact nature of patients' interaction with a hospital pharmacist was not explored. Patients were recruited from patient care units in 9 of 12 hospitals in the health authority, representing a majority of potential points of access to care from the pharmacy teams. Patients' open-ended responses in the phone survey were recorded by interviewers, which allowed them free expression of thought when answering the survey question.

The study had several limitations. First, patients were unaware during their admission that they would be asked to 
recall interactions with a pharmacist and their level of satisfaction with such interaction or to reflect on perceived needs for services delivered to them by hospital pharmacists. Second, once invited and having given consent to participate in the phone survey, respondents were given no advance notice of the questions, had no time to prepare answers, and had limited time to reflect before responding. Third, the duration of the interval between discharge from hospital and participation in the phone survey ranged from 5 to 7 months, which might have led to gaps in their memory of what information was or could have been most helpful in the period immediately following discharge from hospital. Finally, some of the responses categorized as "self-disclosure" could represent misinterpretation of the question by those interviewed. Despite these limitations, it is felt that the findings remain relevant in identifying former inpatients' expectations for pharmacy services that might be beneficial to them in managing their medications.

\section{CONCLUSIONS}

Responses to a phone questionnaire of former inpatients concerning preferences for hospital pharmacy services showed that patients' needs for information about medications most frequently fell in the categories of "general information" and "potential adverse effects". Patients were mainly concerned about receiving a list of their current medications, along with information about why they needed the medications and potential side effects. Moreover, the pattern of responses highlighted that patients seemed unaware of the diversity of services that could be provided by hospital pharmacists. Future work in this area should offer patients a guiding list of topics for current or future hospital-based services, to establish whether these services are desired and acceptable to patients and whether such services could enhance patients' optimal use of medications following discharge.

\section{References}

1. Morecroft CW, Caldwell NA, Mottram D, Thornton D. Patients' expectations of hospital pharmacy services: quantitative study [abstract]. Int J Pharm Pract. 2009;17(Suppl 1):A13.

2. Morecroft CW, Thornton D, Caldwell NA, Voruganti R, McCann D, Blackwell R, et al. Inpatients' expectations of pharmacy services: qualitative study [abstract]. Pharm World Sci. 2008;30(6):1032-3.

3. Kucukarslan S, Schommer JC. Patients' expectations and their satisfaction with pharmacy services. J Am Pharm Assoc. 2002;42(3):489-96.

4. Wilcock M, Harding G. Patients' experience of hospital pharmaceutical services. Int J Pharm Pract. 2011;19(6):400-7.

5. Schommer JC, Wenzel RG, Kucukarslan SN. Evaluation of pharmacists' services for hospital inpatients. Am J Health Syst Pharm. 2002; 59(17):1632-7.
6. Schommer JC. Patients' expectations and knowledge of patient counseling services that are available from pharmacists. Am J Pharm Educ. 1997; 61(4):402-6.

7. Kucukarslan SN, Nadkarni A. Evaluating medication-related services in a hospital setting using the disconfirmation of expectations model of satisfaction. Res Soc Adm Pharm. 2008;4(1):12-22.

8. Worley MM, Schommer JC, Brown LM, Hadsall RS, Ranelli PL, Stratton TP, et al. Pharmacists' and patients' roles in the pharmacistpatient relationship: are pharmacists and patients reading from the same relationship script? Res Soc Adm Pharm. 2007;3(1):47-69.

9. Romonko Slack L, Ing L. Prevalence and satisfaction of discharged patients who recall interacting with a pharmacist during a hospital stay. Can J Hosp Pharm. 2009;62(3):204-8.

10. MacAulay S, Saulnier L, Gould O. Provision of clinical pharmacy services in the home to patients recently discharged from hospital: a pilot project. Can J Hosp Pharm. 2008;61(2):103-13.

11. Borgsteede SD, Karapinar-Carkit F, Hoffmann E, Zoer J, van den Bemt PMLA. Information needs about medication according to patients discharged from a general hospital. Patient Educ Couns. 2011;83(1):22-8.

12. Doucette D, Goodine C, Symes J, Clarke E. Patients' recall of interaction with a pharmacist during hospital admission. Can J Hosp Pharm. 2013;66(3):171-6.

13. Lwanga SK, Lemeshow S. Sample size determination in health studies: a practical manual. Geneva (Switzerland): World Health Organization; 1991.

14. Gravetter FJ, Wallnau LB. Statistics for the behavioral sciences. 8th ed. Belmont (CA): Wadsworth; 2009.

Odette Gould, PhD, is Associate Professor in the Department of Psychology, Mount Allison University, Sackville, New Brunswick.

Paula Buckley, BSc(Honours), was, at the time this study was conducted, a student in the Bachelor of Science (Honours) program in the Department of Psychology, Mount Allison University, Sackville, New Brunswick.

Douglas Doucette, RPh, BSc(Pharm), PharmD, FCSHP, is Regional Pharmacy Clinical Manager, Pharmacy Services, Horizon Health Network, New Brunswick, and Associate Professor, College of Pharmacy, Dalhousie University, Halifax, Nova Scotia.

Competing interests: Douglas Doucette has received payment from Eli Lilly for board membership with the Hospital Pharmacy in Canada Report, speaker's fees from AstraZeneca, and payment from Rogers Publishing for manuscript preparation for the journal Pharmacy Practice. None declared for other authors.

\section{Address correspondence to:}

Dr Douglas Doucette

Pharmacy Services, Horizon Health Network

135 MacBeath Avenue

Moncton NB E1C $6 Z 8$

e-mail: Douglas.Doucette@HorizonNB.ca

Acknowledgements: This study was supported by a grant to Horizon Health Network from Medbuy.

We thank all of the patients for their contributions to this project and the pharmacy students for their assistance with the telephone interviews. 